\title{
Paclitaxel-coated balloon catheter compared with drug- eluting stent for drug-eluting stent restenosis in routine clinical practice
}

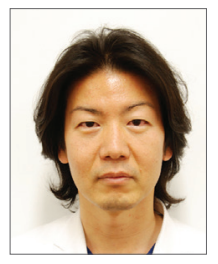

\author{
Seiji Habara*, MD; Kazushige Kadota, MD; Takenori Kanazawa, MD; Tahei Ichinohe, MD; \\ Shunsuke Kubo, MD; Yusuke Hyodo, MD; Suguru Otsuru, MD; Daiji Hasegawa, MD; \\ Takeshi Tada, MD; Hiroyuki Tanaka, MD; Yasushi Fuku, MD; Tsuyoshi Goto, MD; \\ Kazuaki Mitsudo, MD \\ Department of Cardiology, Kurashiki Central Hospital, Kurashiki, Japan
}

This paper also includes supplementary data published online at: http://www.pcronline.com/eurointervention/94th_issue/223

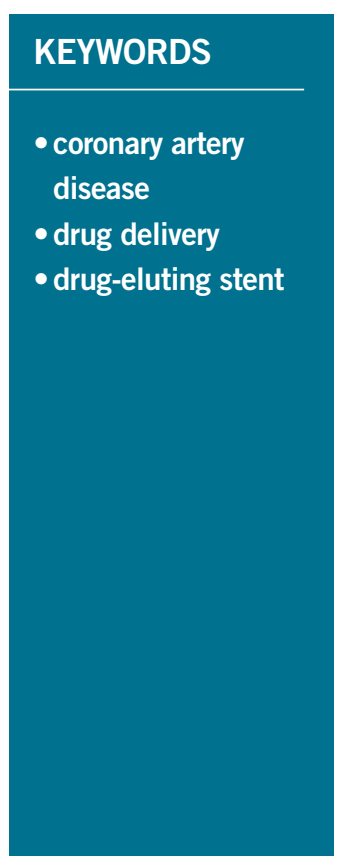

\begin{abstract}
Aims: The aim of this study was to compare the efficacy between paclitaxel-coated balloon (PCB) and drugeluting stent (DES) implantation for the treatment of DES restenosis in complex situations.

Methods and results: Data of patients who received revascularisation for DES restenosis between 2004 and 2011 were collected. A total of 683 patients with 777 lesions were analysed in this study (306 lesions treated by PCB, 471 lesions by DES). The use of PCB or DES was at the discretion of the operator. Angiographic outcomes at six to eight months and clinical outcomes at 12-month follow-up were compared between groups. The primary outcome was binary restenosis. Cox regression analysis with propensity score adjustment suggested that there were no significant differences between the two groups with respect to binary restenosis, target lesion revascularisation (TLR), and major adverse cardiac events. As for the angiographic endpoints, subgroup analysis was performed for several parameters. There was a significant trend favouring PCB with respect to binary restenosis and TLR in non-focal type lesions and bifurcation lesions.
\end{abstract}

Conclusions: Angiographic and clinical outcomes in the PCB group were similar to those in the repeat DES group. PCB seemed to offer more favourable results in non-focal type lesions and bifurcation lesions.

\footnotetext{
*Corresponding author: Department of Cardiology Kurashiki Central Hospital, 1-1-1 Miwa, Kurashiki-shi, Okayama, 710-8602, Japan.E-mail:sh10461@kchnet.or.jp
} 


\section{Introduction}

As drug-eluting stents (DES) are used in complex settings, DES restenosis is an important issue after percutaneous coronary intervention. Its optimal treatment remains undefined. The various aetiologies of DES restenosis and the variety of possible therapeutic options make it difficult for interventional cardiologists to determine the optimal therapy. Nowadays, the paclitaxel-coated balloon (PCB) has emerged as a potential alternative to the current treatment of in-stent restenosis (ISR) ${ }^{1-6}$. A recent study has shown that PCB is not inferior to repeat stenting using paclitaxel-eluting stents for limus-eluting stent restenosis ${ }^{5}$. However, there are currently inadequate data to compare $\mathrm{PCB}$ with repeat stenting using several DES for restenosis in several DES in complex clinical and angiographic scenarios. The aim of this study was to compare efficacy between PCB and DES implantation for the treatment of DES restenosis in an unselected and consecutive patient cohort.

\section{Methods \\ PATIENT POPULATION}

Data from patients who underwent revascularisation for DES restenosis at Kurashiki Central Hospital between September 2004 and November 2011 were retrospectively analysed. The exclusion criteria were recurrent lesions after DES for ISR, a mixture of different types of DES, lesions located in bypass conduits, and bail-out stenting after the use of PCB due to major dissection. The use of PCB or DES (stent selection) was at the discretion of the operator. A sirolimus-eluting stent (SES) (CYPHER ${ }^{\circledR}$; Cordis, Johnson \& Johnson, Miami Lakes, FL, USA) was the only DES available in Japan during the period from August 2004 to March 2007. A paclitaxel-eluting stent (PES) (TAXUS'M; Boston Scientific Corp., Marlborough, MA, USA) became available in April 2007, and from then SES and PES were used. A PCB (SeQuent ${ }^{\circledR}$ Please balloon catheter; B. Braun, Melsungen, Germany) became available in September 2008, and from then the PCB was mainly used. An everolimus-eluting stent (EES) (XIENCE V; Abbott Vascular Devices, Redwood City, CA, USA, and PROMUSTM; Boston Scientific Corp.) became available in January 2010, and from then EES and PCB were used. Fifty-one patients from our previous study ${ }^{3,6}$ were included in this study. The study was carried out in accordance with the provisions of the Declaration of Helsinki and local regulations. All patients provided informed consent for both the procedure and subsequent data collection and analysis for research purposes, and the study was approved by the institutional ethics committee.

\section{INTERVENTIONAL PROCEDURE}

All patients were pretreated with aspirin (100 mg daily) and ticlopidine (200 mg daily)/clopidogrel (75 mg daily). Aspirin and ticlopidine/clopidogrel treatment was recommended for at least three months in the PCB group, and 12 months in the repeat DES group. The procedures were performed according to standard clinical guidelines. In all cases, the interventional strategy and the use of adjunctive devices and pharmacotherapy were at the discretion of the operator. Predilatation with a high-pressure balloon was performed for all ISR lesions. The length of PCB or DES was chosen to overlap the lesion by at least $2 \mathrm{~mm}$ at the proximal and distal margins. The recommended inflation time for PCB was 60 seconds.

\section{FOLLOW-UP AND DEFINITION}

All patients were scheduled to undergo repeat angiography six to eight months after a successful procedure. The follow-up angiogram was obtained earlier if clinically indicated. Clinical follow-up was performed by telephone contact or office visit 12 months after the index procedure. Binary restenosis at follow-up was defined as a stenosis occupying more than $50 \%$ of the diameter by quantitative coronary angiographic analysis. Target lesion revascularisation (TLR) was defined as any repeat percutaneous coronary intervention or aortocoronary bypass surgery because of restenosis (diameter stenosis $\geq 50 \%$ ) associated with symptoms or objective signs of ischaemia (exercise test, exercise nuclear myocardial perfusion imaging, and fractional flow reserve). Death from any causes, non-fatal acute myocardial infarction, and TLR were considered to be major adverse cardiac events (MACE). We applied Academic Research Consortium criteria for definite stent thrombosis for adjudication of target lesion thrombosis.

\section{ANGIOGRAPHIC ANALYSIS}

Serial coronary angiography was performed at baseline (before and after the intervention) and at six- to eight-month followup. Quantitative coronary angiographic analysis was performed using QCA-CMS (Medis Medical Imaging Systems, Leiden, The Netherlands). Reference diameter, minimal lumen diameter, percentage diameter stenosis, and lesion length were measured before and after the intervention, and at follow-up. Acute gain was defined as minimal lumen diameter immediately after the procedure minus that at baseline. Late lumen loss was defined as minimal lumen diameter immediately after the procedure minus that at angiographic follow-up. Measurements were carried out at the target lesion treated by PCB or stent within $5 \mathrm{~mm}$ proximal and distal to the treated area. ISR was classified according to the Mehran classification? ${ }^{7}$ Multifocal, diffuse, proliferative, and occlusive lesions were classified as nonfocal type restenosis lesions. Stent fracture was angiographically defined at the time of use of the PCB or repeat DES.

\section{STUDY ENDPOINTS}

The clinical endpoints included TLR, cardiac death, myocardial infarction, target lesion thrombosis, and MACE at 12-month follow-up. The clinical endpoints were evaluated on a per patient basis. The angiographic endpoints included late lumen loss and the rate of binary restenosis at six- to eight-month follow-up. The angiographic endpoints were evaluated on a per lesion basis. The primary outcome was binary restenosis. The secondary outcomes included clinical outcomes (TLR, cardiac death, myocardial infarction, target lesion thrombosis, and MACE) and late lumen loss.

\section{STATISTICAL ANALYSIS}

Continuous variables are expressed as mean \pm standard deviation. Values are reported as numbers with relative percentages or 
standard deviation. For continuous data, groups were compared by parametric Student's t-test or non-parametric Mann-Whitney $\mathrm{U}$ test according to the distribution of data. Categorical variables were compared by $\chi^{2}$ test. P-values of less than 0.05 were considered to be statistically significant. In order to reduce the treatment bias and potential confounding factors, we performed propensity score matching. The propensity score was estimated by multiple logistic regression analysis using the variables for controlling the potential bias in the comparison between PCB and repeat DES groups. Using propensity scoring, the patients with lesions treated by DES were matched one to one with the patients treated by PCB with similar baseline characteristics. Angiographic and clinical outcomes were compared with adjustment using the Cox proportional hazards model. For subgroup analysis of angiographic outcomes, the logistic regression model was used to assess the interaction between the treatment and each subgroup. Subgroup analyses were performed for the entire cohort. The variables used in the propensity score and multivariable analyses were selected when they were shown to affect dependent variables in the univariate analysis or empirically, if they were known to have predictive values: gender, age, diabetes mellitus, acute coronary syndromes, haemodialysis, bifurcation lesion, aorto-ostial lesion, stent edge restenosis, stent fracture, reference diameter, and ISR pattern (focal or non-focal). All statistical analyses were performed using IBM SPSS Statistics for Windows, version 20.0 (IBM Corp, Armonk, NY, USA), and EZR (Saitama Medical Center, Jichi Medical University, Saitama, Japan) which is a graphical user interface for R, version 2.13.0 (The R Foundation for Statistical Computing, Vienna, Austria).

\section{Results}

\section{BASELINE AND PROCEDURAL DATA}

Among a total of 685 patients with 777 lesions after re-revascularisation for DES restenosis, 260 patients with 306 lesions were treated by PCB, and 425 patients with 471 lesions by DES. Among these lesions, $64.2 \%(n=499)$ originally received a sirolimus-eluting stent, $18.3 \%(\mathrm{n}=142)$ a paclitaxel-eluting stent, $8.6 \%$ $(\mathrm{n}=67)$ a zotarolimus-eluting stent, $5.7 \%(\mathrm{n}=44)$ an everolimuseluting stent and $3.2 \%(n=25)$ a biolimus-eluting stent. Online Table 1 shows baseline clinical, angiographic, and procedural characteristics in the PCB and repeat DES groups. Among 471 lesions in the repeat DES group, $177(37.6 \%)$ were treated by SES, $164(34.8 \%)$ by PES, and $130(27.6 \%)$ by EES. No significant differences were observed in clinical characteristics between the two groups, except the incidence of acute coronary syndrome. Non-focal type restenosis and bifurcation lesions were more frequent in the PCB group. Stent edge restenosis was more frequent in the repeat DES group. Quantitative coronary angiographic results are summarised in Online Table 2. Reference diameter was significantly greater in the repeat DES group $(2.89 \pm 0.43 \mathrm{~mm}$ vs. $2.99 \pm 0.48 \mathrm{~mm}, \mathrm{p}=0.001)$. Lesion length was significantly longer in the PCB group $(17.1 \pm 8.6 \mathrm{~mm}$ vs. $15.7 \pm 11.1 \mathrm{~mm}, \mathrm{p}=0.046)$. Percentage diameter stenosis and minimal lumen diameter at pre-procedure were similar between the two groups. In the PCB group, post-intervention minimal lumen diameter was significantly lower $(2.08 \pm 0.45 \mathrm{~mm}$ vs. $2.64 \pm 0.49 \mathrm{~mm}, \mathrm{p}<0.001)$, percentage diameter stenosis significantly greater $(28.8 \pm 9.6 \%$ vs. $15.1 \pm 8.8 \%, \mathrm{p}<0.001)$, and acute gain significantly greater $(1.27 \pm 0.62 \mathrm{~mm}$ vs. $1.78 \pm 0.66 \mathrm{~mm}, \mathrm{p}<0.001)$.

\section{ANGIOGRAPHIC RESULTS}

Follow-up angiography was performed in 690 lesions (88.8\%). Quantitative coronary angiographic results are summarised in Online Table 3. Recurrent restenosis occurred in $23.5 \%$ of the PCB group and $25.9 \%$ of the repeat DES group $(p=0.48)$. The incidence of TLR (per lesions) was noted in $15.7 \%$ of the PCB group and in $20.3 \%$ of the repeat DES group $(p=0.13)$. Late lumen loss was lower in the PCB group than in the repeat DES group $(0.34 \pm 0.57 \mathrm{~mm}$ vs. $0.68 \pm 0.76 \mathrm{~mm}, \mathrm{p}<0.001)$. There were trends favouring PCB with respect to binary restenosis (adjusted HR $0.81,95 \%$ CI: $0.58-1.11$, $\mathrm{p}=0.19$ ) and TLR (adjusted HR 0.70, 95\% CI: 0.47-1.02, $\mathrm{p}=0.06$ ).

\section{CLINICAL OUTCOMES}

Clinical follow-up 12 months after intervention was performed in 680 patients $(99.3 \%)$. Online Table 3 shows clinical outcomes. The incidence of TLR (per patient) was noted in $16.7 \%$ of the PCB group and $19.4 \%$ of the repeat DES group $(p=0.41)$. There was no death, myocardial infarction or target lesion thrombosis in the PCB group. The MACE rate during the 12-month follow-up in the PCB and repeat DES groups was $16.7 \%$ and $20.1 \%$, respectively $(p=0.27)$. In the PCB group, all MACE were due to repeat revascularisation procedures.

\section{PROPENSITY SCORE MATCHED ANALYSIS}

After performing propensity score matching, a total of 236 matched pairs were generated. The $\mathrm{C}$ statistic of the propensity score model was 0.726 and the Hosmer-Lemeshow test p-value was 0.510 . Table 1 and Table 2 show baseline clinical, angiographic and procedural characteristics, and quantitative coronary angiographic data in the PCB and repeat DES groups after propensity score matching. No significant differences were observed in clinical and angiographic characteristics between the two groups. Reference diameter, percentage diameter stenosis, minimal lumen diameter and lesion length at pre-procedure in the PCB group were similar to those in the repeat DES group. Table 3 shows quantitative coronary angiographic results and clinical outcomes. Late lumen loss was lower in the PCB group than in the repeat DES group $(0.37 \pm 0.59 \mathrm{~mm}$ vs. $0.73 \pm 0.83 \mathrm{~mm}, \mathrm{p}<0.001)$. Figure 1 shows the cumulative frequency distribution of the percentage diameter stenosis before and after the procedure as well as at angiographic follow-up. Although the proportion of a residual percentage diameter stenosis of $>30 \%$ after treatment was higher in the PCB group, the percentage diameter stenosis at angiographic follow-up was similar between the two groups ( $41.9 \pm 19.5 \%$ vs. $39.0 \pm 25.8 \%, \mathrm{p}=0.19)$. Figure 2 shows kernel density estimation of the percentage diameter stenosis at angiographic follow-up. In the PCB group, it was distributed primarily 
Table 1. Baseline clinical, angiographic and procedural characteristics (propensity-matched population).

\begin{tabular}{|c|c|c|c|}
\hline Propensity-matched population & $\begin{array}{c}\text { PCB } \\
236 \text { lesions }\end{array}$ & $\begin{array}{l}\text { Repeat DES } \\
236 \text { lesions }\end{array}$ & $p$-value \\
\hline Age, yrs & $69.0 \pm 10.3$ & $68.2 \pm 11.2$ & 0.46 \\
\hline Male gender, $\mathrm{n}(\%)$ & $178(75.4)$ & $184(78.0)$ & 0.59 \\
\hline Diabetes mellitus, $n(\%)$ & $119(50.4)$ & $128(54.2)$ & 0.46 \\
\hline Hypertension, n (\%) & $188(79.7)$ & $178(75.4)$ & 0.32 \\
\hline Hyperlipidaemia, n (\%) & $142(60.2)$ & $146(61.9)$ & 0.78 \\
\hline Current smoker, n (\%) & $9(3.8)$ & $12(5.1)$ & 0.66 \\
\hline Haemodialysis, n (\%) & 27 (11.4) & $23(9.8)$ & 0.65 \\
\hline Acute coronary syndrome, n (\%) & $23(9.8)$ & $29(12.3)$ & 0.46 \\
\hline Stable angina, $\mathrm{n}(\%)$ & $213(90.3)$ & $207(87.7)$ & 0.46 \\
\hline Multivessel disease, $n(\%)$ & $65(27.5)$ & $60(25.4)$ & 0.68 \\
\hline Previous myocardial infarction, n (\%) & $118(50.0)$ & $132(55.9)$ & 0.23 \\
\hline Previous bypass surgery, $n$ (\%) & $21(8.9)$ & $16(6.8)$ & 0.49 \\
\hline Target lesion & & & 0.10 \\
\hline Left anterior descending, n (\%) & $93(39.4)$ & $82(29.7)$ & \\
\hline Left circumflex, n (\%) & $37(15.7)$ & $41(14.9)$ & \\
\hline Right, n (\%) & $100(42.4)$ & $125(53.0)$ & \\
\hline Left main trunk, $n(\%)$ & $6(2.5)$ & $4(1.7)$ & \\
\hline Classification of in-stent restenosis & & & 0.07 \\
\hline Focal margin, $n(\%)$ & $5(2.1)$ & $8(3.4)$ & \\
\hline Focal body, n (\%) & $87(36.9)$ & $95(40.3)$ & \\
\hline Multifocal, n (\%) & $7(3.0)$ & $10(4.2)$ & \\
\hline Diffuse, $n(\%)$ & $103(43.6)$ & 76 (32.2) & \\
\hline Proliferative, $n(\%)$ & $17(7.2)$ & $15(6.4)$ & \\
\hline Occlusive, n (\%) & $17(7.2)$ & $32(13.6)$ & \\
\hline Focal type restenosis, n (\%) & $92(39.0)$ & $103(43.6)$ & 0.35 \\
\hline Non-focal type restenosis, n (\%) & $144(61.0)$ & $133(56.4)$ & 0.35 \\
\hline Stent edge restenosis, n (\%) & $22(9.3)$ & $23(9.8)$ & $>0.99$ \\
\hline Aorto-ostial lesion, $n(\%)$ & $16(6.8)$ & $16(6.8)$ & $>0.99$ \\
\hline Bifurcation lesion, $n$ (\%) & $60(25.4)$ & $42(17.8)$ & 0.06 \\
\hline Stent fracture, $n(\%)$ & $38(16.1)$ & $52(22.0)$ & 0.13 \\
\hline Previous DES type & & & 0.07 \\
\hline Paclitaxel-eluting stent & $40(17.0)$ & $57(24.2)$ & \\
\hline \multicolumn{4}{|l|}{ Limus-eluting stent } \\
\hline Sirolimus-eluting stent & $119(50.4)$ & $162(68.6)$ & \\
\hline Zotarolimus-eluting stent & $36(15.3)$ & $9(3.8)$ & \\
\hline Everolimus-eluting stent & $30(12.7)$ & $2(0.9)$ & \\
\hline Biolimus-eluting stent & $11(4.7)$ & $6(2.5)$ & \\
\hline \multicolumn{4}{|l|}{ DES used for in-stent restenosis } \\
\hline Sirolimus-eluting stent & - & $84(35.6)$ & \\
\hline Paclitaxel-eluting stent & - & $77(32.6)$ & \\
\hline Everolimus-eluting stent & - & $75(31.8)$ & \\
\hline Stent diameter (mm) & - & $2.94 \pm 0.37$ & \\
\hline Stent total length (mm) & - & $19.9 \pm 9.9$ & \\
\hline Multiple stents, n (\%) & - & $14(5.9)$ & \\
\hline \multicolumn{4}{|l|}{ Paclitaxel-coated balloon } \\
\hline Balloon diameter (mm) & $2.90 \pm 0.45$ & - & \\
\hline Balloon total length (mm) & $21.9 \pm 9.0$ & - & \\
\hline Multiple balloons, n (\%) & $11(4.7)$ & - & \\
\hline
\end{tabular}

Table 2. Quantitative coronary angiographic analysis results.

\begin{tabular}{|c|c|c|c|}
\hline $\begin{array}{c}\text { Propensity-matched } \\
\text { population }\end{array}$ & $\begin{array}{c}\text { PCB } \\
\text { 236 lesions }\end{array}$ & $\begin{array}{c}\text { Repeat DES } \\
\text { 236 lesions }\end{array}$ & p-value \\
\hline Pre-procedure \\
\hline Diameter stenosis (\%) & $71.2 \pm 17.1$ & $70.6 \pm 17.4$ & 0.71 \\
\hline Minimal lumen diameter (mm) & $0.83 \pm 0.52$ & $0.86 \pm 0.54$ & 0.61 \\
\hline Reference diameter (mm) & $2.92 \pm 0.44$ & $2.95 \pm 0.44$ & 0.45 \\
\hline Lesion length (mm) & $16.4 \pm 8.4$ & $15.6 \pm 8.8$ & 0.30 \\
\hline Post procedure & $28.1 \pm 9.6$ & $14.8 \pm 8.5$ & $<0.001$ \\
\hline Diameter stenosis (\%) & $2.12 \pm 0.45$ & $2.62 \pm 0.47$ & $<0.001$ \\
\hline Minimal lumen diameter (mm) & $1.29 \pm 0.62$ & $1.76 \pm 0.65$ & $<0.001$ \\
\hline Acute gain (mm) & \multicolumn{3}{l}{} \\
\hline DES: drug-eluting stent; PCB: paclitaxel-coated balloon \\
\hline
\end{tabular}

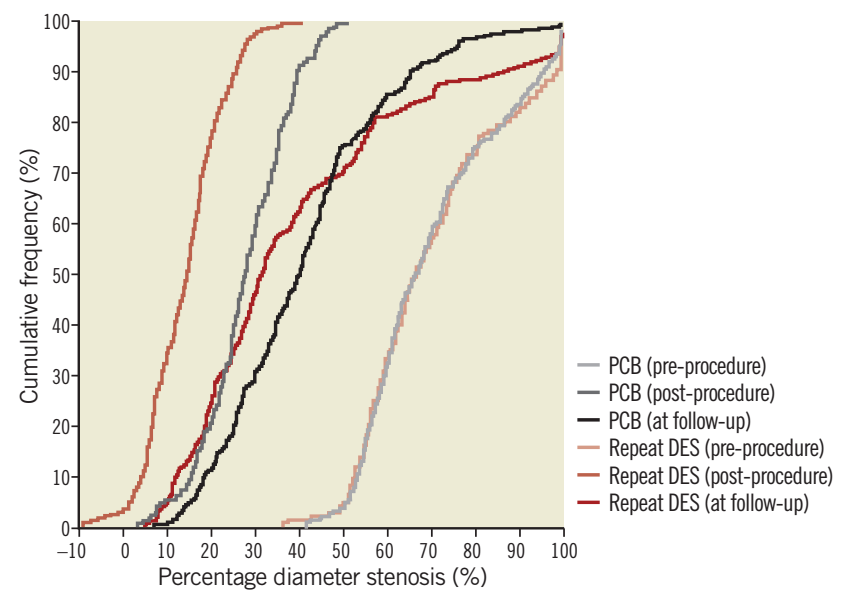

Figure 1. Cumulative frequency distribution of percentage diameter stenosis. DES: drug-eluting stent; PCB: paclitaxel-coated balloon

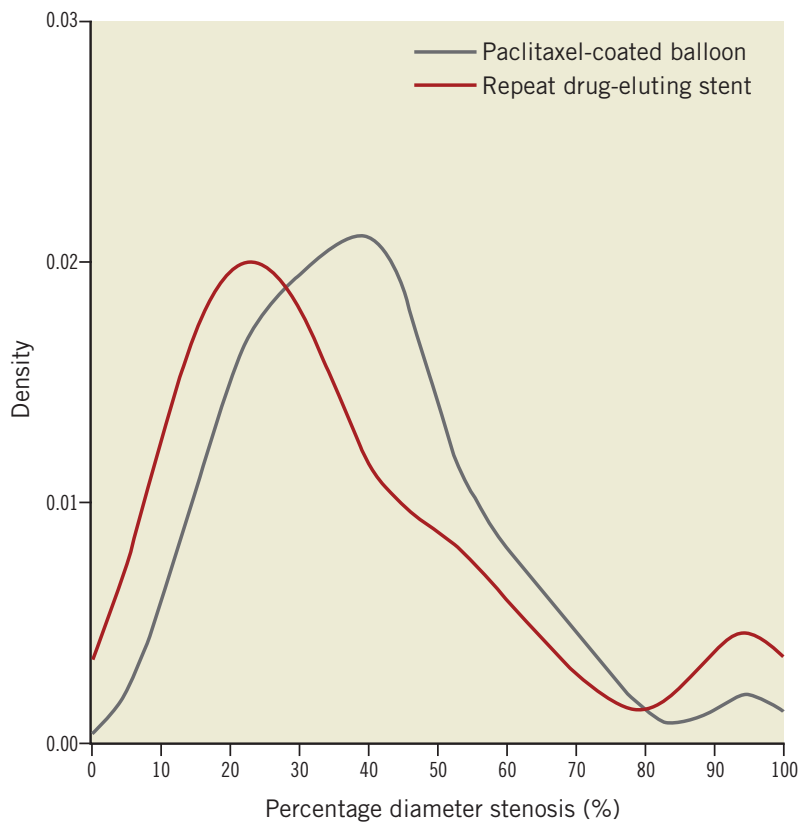

Figure 2. Percentage diameter stenosis at angiographic follow-up. 
from $30 \%$ to $60 \%$ diameter stenosis after treatment. There were no significant differences between the two groups with respect to binary restenosis (HR 0.99, 95\% CI: 0.69-1.43, p=0.97), TLR (HR $0.86,95 \%$ CI: $0.55-1.33, \mathrm{p}=0.49$ ), and MACE (HR 0.76, 95\% CI: $0.49-1.18, \mathrm{p}=0.23$ ).

\section{SUBGROUP ANALYSIS}

As for the angiographic endpoint of binary restenosis and TLR, subgroup analysis was performed for several parameters. HRs with respect to binary restenosis and TLR in several subgroups are illustrated in Figure 3. Logistic regression-adjusted angiographic results of both strategies were compared. PCB was more effective in non-focal type restenosis and bifurcation lesions than in repeat DES. The treatment effect was neutral between PCB and repeat DES in other subgroups. In the non-focal restenosis lesion cohort, late lumen loss $(0.38 \pm 0.56 \mathrm{~mm}$ vs. $0.89 \pm 0.88 \mathrm{~mm}, \mathrm{p}<0.0001)$, binary restenosis $(25.4 \%$ [48/189] vs. $40.9 \%$ [76/186], $\mathrm{p}=0.002)$, and TLR (17.5\% [33/189] vs. $31.2 \%$ [58/186], $\mathrm{p}=0.003)$ were significantly better in the PCB group than in the repeat DES group. In the focal restenosis lesion cohort, late lumen loss was lower in the PCB group than in the repeat DES group $(0.26 \pm 0.59 \mathrm{~mm}$ vs. $0.51 \pm 0.60 \mathrm{~mm}, \mathrm{p}<0.001)$. However, the incidences of binary restenosis $(19.6 \%$ [18/92] vs. $13.5 \%$ [30/223], $\mathrm{p}=0.17)$, and TLR $(12.0 \%$ [11/92] vs. $11.2 \%$ [25/223], $\mathrm{p}=0.85)$ were similar in both groups. In the bifurcation lesion cohort, late lumen loss $(0.39 \pm 0.56 \mathrm{~mm}$ vs. $0.97 \pm 0.99 \mathrm{~mm}, \mathrm{p}<0.0001)$, and TLR $(11.6 \%$ [8/69] vs. $31.2 \%$ $[20 / 61], p=0.005)$ were significantly better in the PCB group than in the repeat DES group. The incidence of binary restenosis $(26.1 \%$ [18/69] vs. $39.3 \%$ [24/61], $\mathrm{p}=0.13$ ) tended to be lower in the PCB group than in the repeat DES group. In the stent edge restenosis cohort, there was a tendency towards a higher angiographic restenosis rate $(30.4 \%[7 / 23]$ vs. $14.3 \%$ [14/98], $\mathrm{p}=0.12)$ and TLR rate $(26.1 \%$ [6/23] vs. $12.2 \%$ [12/98], $\mathrm{p}=0.11)$ in the PCB group than in the repeat DES group.

\section{FIRST-GENERATION DES VS. SECOND-GENERATION DES FOR DES RESTENOSIS}

Among 471 lesions in the repeat DES group, 341 (72.4\%) were treated using first-generation DES (SES or PES) and 130 (27.6\%) using second-generation DES (EES). No significant difference in binary restenosis $(25.7 \%$ vs. $26.6 \%, \mathrm{p}=0.90)$, TLR $(20.6 \%$ vs. $19.5 \%, \mathrm{p}=0.89)$ or late lumen loss $(0.70 \pm 0.75 \mathrm{~mm}$ vs. $0.65 \pm 0.81 \mathrm{~mm}$, $\mathrm{p}=0.60)$ was observed between first- and second-generation DES.

\section{THE DIFFERENCE IN ANGIOGRAPHIC OUTCOMES ACCORDING TO TYPE OF RESTENOTIC STENT}

In the PCB group, $83.3 \%(n=255)$ originally received a limuseluting stent, and $16.7 \%(\mathrm{n}=51)$ a paclitaxel-eluting stent. No significant difference was observed in binary restenosis $(22.3 \%$ vs. $29.2 \%, \mathrm{p}=0.35)$, TLR ( $14.6 \%$ vs. $20.8 \%, \mathrm{p}=0.28)$ or late lumen loss $(0.33 \pm 0.57 \mathrm{~mm}$ vs. $0.39 \pm 0.57 \mathrm{~mm}, \mathrm{p}=0.46)$ between limus-eluting and paclitaxel-eluting stents.

\section{Discussion}

The main findings of this study were as follows. First, angiographic and clinical outcomes after propensity score matching, including binary restenosis, TLR, and MACE, were similar in both PCB and repeat DES groups. Second, whereas PCB and repeat DES showed similarly effective results for focal type DES restenosis, PCB was superior to repeat DES for non-focal type DES restenosis and bifurcation lesions. A recent study has confirmed that, in patients with DES restenosis, DES implantation provides superior results to conventional angioplasty ${ }^{8}$. Repeat stent implantation presents a serious problem in that the treatment of recurrent restenosis is limited because of multiple layers of metal in the coronary artery. Nowadays, PCB has emerged as a potential alternative to the current treatment of ISR ${ }^{1-6}$. The PEPCAD II trial which evaluated the comparative efficacy between PCB and repeat stenting with PES for bare metal stent restenosis showed that PCB is non-inferior to

Table 3. Angiographic and clinical outcomes at 6 to 8-month follow-up.

\begin{tabular}{|c|c|c|c|c|c|}
\hline Propensity-matched population & $\begin{array}{c}\text { PCB } \\
236 \text { lesions }\end{array}$ & $\begin{array}{l}\text { Repeat DES } \\
236 \text { lesions }\end{array}$ & $p$-value & Unadjusted HR (95\% CI) & $p$-value \\
\hline Angiographic follow-up at 6 to 8 months (per lesion) & $214 / 236(90.7 \%)$ & $208 / 236(88.1 \%)$ & & & \\
\hline Diameter stenosis (\%) & $41.9 \pm 19.5$ & $39.0 \pm 25.8$ & 0.19 & & \\
\hline Minimal lumen diameter $(\mathrm{mm})$ & $1.75 \pm 0.69$ & $1.91 \pm 0.86$ & 0.03 & & \\
\hline Late luminal loss (mm) & $0.37 \pm 0.59$ & $0.73 \pm 0.83$ & $<0.001$ & & \\
\hline Binary restenosis, $\mathrm{n}(\%)$ & $55(25.7)$ & $61(29.3)$ & 0.45 & $0.99(0.69-1.43)$ & 0.97 \\
\hline Target lesion revascularisation, $\mathrm{n}(\%)$ & $36(16.8)$ & $44(21.2)$ & 0.27 & $0.86(0.55-1.33)$ & 0.49 \\
\hline Clinical follow-up at 12 months (per lesion) & $234 / 236(99.2 \%)$ & $232 / 236(98.3 \%)$ & & & \\
\hline Target lesion revascularisation, $\mathrm{n}(\%)$ & $37(15.8)$ & $46(19.8)$ & 0.28 & $0.78(0.51-1.21)$ & 0.27 \\
\hline Cardiac-related death, n (\%) & $0(0)$ & $3(1.3)$ & 0.12 & - & - \\
\hline Myocardial infarction, n (\%) & $0(0)$ & $1(0.4)$ & 0.50 & - & - \\
\hline Target lesion thrombosis, $\mathrm{n}(\%)$ & $0(0)$ & $1(0.4)$ & 0.50 & - & - \\
\hline MACE, n (\%) & $36(15.4)$ & $46(19.8)$ & 0.23 & $0.76(0.49-1.18)$ & 0.23 \\
\hline
\end{tabular}




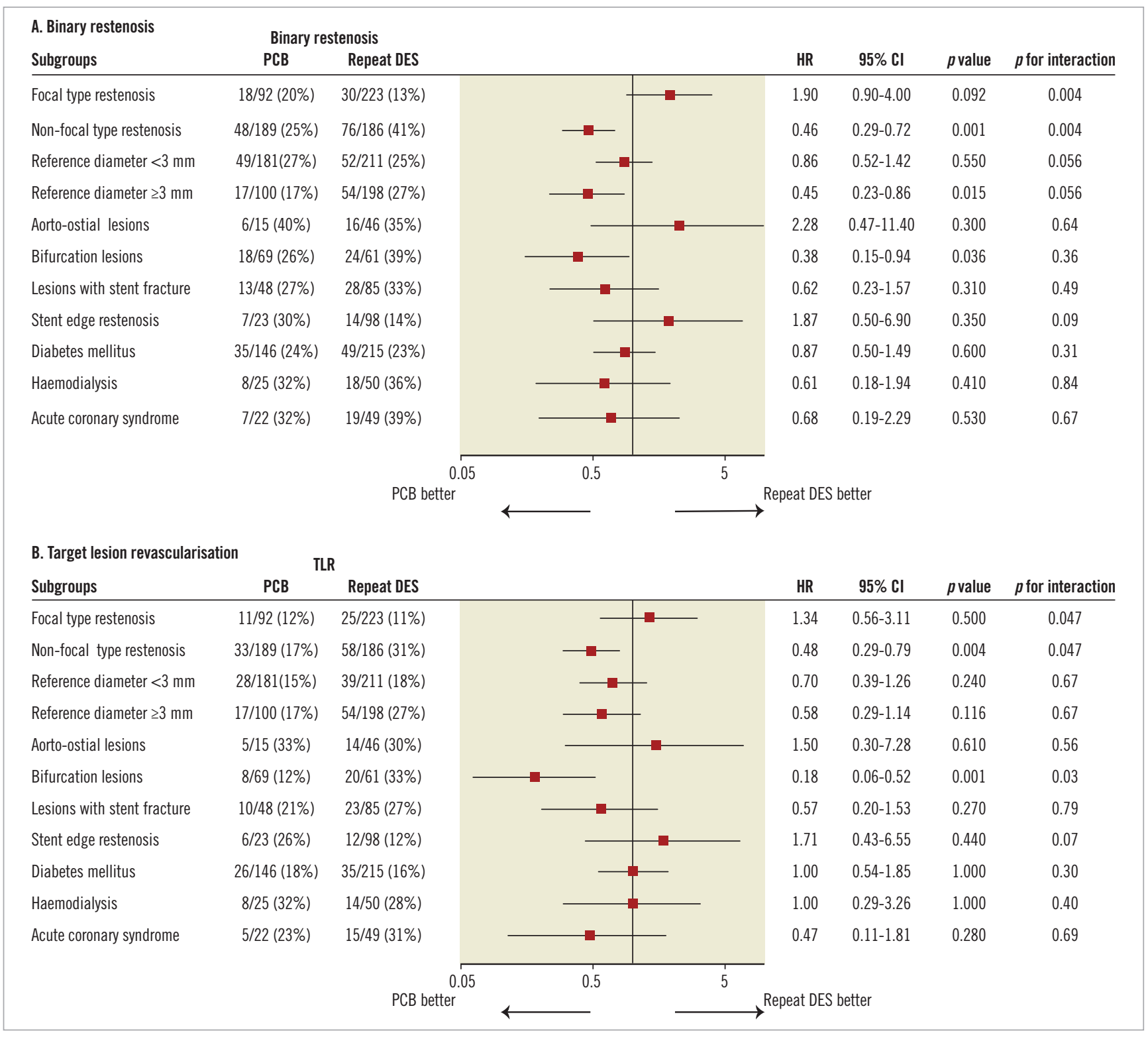

Figure 3. Comparison of binary restenosis (A) and target lesion revascularisation (B) for subgroups. CI: confidence interval; HR: hazard ratios

repeat stenting with $\mathrm{PES}^{2}$. ISAR-DESIRE 3 showed that PCB is not inferior to repeat stenting using PES for DES restenosis ${ }^{5}$. The major limitations of these trials are that the restenosis treated is at relatively low risk, and repeat stenting using PES is regarded as a control group. Therefore, these results are not representative of patients in the "real world". There is no evidence as to whether PCB is going to be able to outperform DES implantation for restenosis in several DES in the "real world". In this study, we compared the efficacy between PCB and DES implantation with several DES for the treatment of restenosis in several DES in an unselected and consecutive patient cohort. There was significantly lower acute gain and lower late lumen loss with the PCB group compared to the repeat DES group. In the PCB group, it was distributed primarily from 30 to $60 \%$ diameter stenosis at angiographic follow-up. In contrast, in the repeat DES group it appeared to be a bimodal distribution. This result was the reason why binary restenosis and TLR were numerically lower with the PCB group, even though diameter stenosis at angiographic follow-up was similar between the two groups. Agostoni and colleagues reported that regression of neointimal volume with time may be caused by the cytotoxic effects of paclitaxel ${ }^{9}$. In the ISAR-DESIRE 3 trial $^{5}$, the angiographic restenosis rate was $27 \%$, and the mean late lumen loss was $0.37 \mathrm{~mm}$ in the PCB-treated lesion. In our study, we found the angiographic restenosis rate was $23.5 \%$, and mean late lumen loss was $0.34 \pm 0.57 \mathrm{~mm}$ in the PCB group. The results of our study were consistent with those of the ISAR-DESIRE 3 trial $^{5}$.

Logistic regression-adjusted angiographic results showed that $\mathrm{PCB}$ was more effective in non-focal restenosis lesions. Some reports suggest that focal DES restenosis may be related to mechanical or technical factors such as stent fracture, localised imperfect 
drug elution, and polymer disruption, whereas diffuse DES restenosis may be related to drug failure ${ }^{10,11}$. PCB allows immediate and homogenous drug transfer to the vessel wall without any polymers, because the absence of a stent respects the original anatomy of the arteries. From this point of view, PCB might be more effective for the treatment of non-focal type DES restenosis than repeat DES implantation.

Logistic regression-adjusted angiographic results also showed that $\mathrm{PCB}$ was more effective in bifurcation lesions. After repeat stent implantation, double layers of metal at the ostium cause a risk of reducing the side branch coronary flow. In addition, in the cases of restenosis after culotte stenting, the main branch shows triple layers of metal after repeat stent implantation. PCB has an option which can approach the side branch. PCB might be more suitable for the treatment of bifurcation lesions than repeat DES implantation.

DES restenosis is sometimes located at the stent edges. The present study included 140 lesions (18\%) with stent edge restenosis. In the stent edge restenosis cohort, there was a tendency towards worse angiographic outcomes in the PCB group than in the repeat DES group. A previous study suggested that repeat DES is superior to balloon angioplasty in stent edge restenosis ${ }^{12}$. No previous study has investigated the efficacy of PCB or repeat stenting in patients with edge restenosis. Stent edge restenosis extends outside the stent. In non-stented vessels, negative vessel remodelling and recoil appear to be the most relevant factors for restenosis ${ }^{13}$. Furthermore, excessive intimal growth and chronic stent recoil appear to be the most relevant factors for restenosis in the aorto-ostial lesion ${ }^{14}$. The scaffolding properties of stents may provide a better angiographic outcome in the restenosis caused by remodelling or recoil.

In the repeat DES group, second-generation DES were used in $28 \%$ of lesions treated for DES restenosis. The RIBS V trial ${ }^{15}$ reported that second-generation DES showed superiority in terms of angiographic outcomes compared with paclitaxel-coated balloons for BMS-ISR. In our study, the use of second-generation DES was not associated with better angiographic outcomes for DES restenosis. The effect of PCB on DES restenosis was relatively less than that on BMS restenosis ${ }^{6}$. An analysis from the ISAR trial ${ }^{16}$ suggested that drug resistance may play a role in DES restenosis. The differences between the previous stent types may affect the results.

PCB could be used multiple times if recurrent restenosis occurring after an initial restenosis was treated by PCB. From this point of view, PCB might be the next preferred strategy for the treatment of DES restenosis.

\section{Study limitations}

This study was not a randomised study, which might have affected the results. As we performed propensity score matched analyses to adjust for potential confounding factors, we were able to reduce the treatment bias and potential confounding factors.

In our study, non-focal type restenosis was observed in $67.0 \%$ of the PCB group, and $47.5 \%$ of the repeat DES group. The use of $\mathrm{PCB}$ or DES (stent selection) was at the discretion of the operator.
The operator tended to avoid repeat stenting to treat non-focal type restenosis. In DES restenosis, the angiographic pattern of restenosis has been shown to be an important prognostic indicator. Patients with a non-focal pattern of DES restenosis have a higher rate of recurrent restenosis than those with a focal pattern, which carried disadvantages for the PCB group. Multiple lesions per patient were included, which might have affected the analysis of clinical outcomes. The follow-up period of 12 months did not allow exploration of rare events such as target lesion thrombosis. Further long-term data are eagerly awaited. Our findings may not be generalisable to other PCB because we only used the SeQuent Please balloon catheter.

\section{Conclusions}

In patients with DES restenosis, angiographic and clinical outcomes in the PCB group were similar to those in the repeat DES group. PCB seemed to offer more favourable results in non-focal type restenosis lesions and bifurcation lesions.

\section{Impact on daily practice}

Although DES restenosis has been an important issue after percutaneous coronary intervention, the optimal management of DES restenosis remains to be established. The present study shows that $\mathrm{PCB}$ is not inferior to repeat stenting for DES restenosis and PCB may be more effective for the complex lesions. The advantages of PCB for DES restenosis are that multiple layers of metal can be avoided within the previously implanted stent, and PCB can be used multiple times for recurrent restenosis even when the previous restenosis was treated by PCB.

\section{Acknowledgements}

We thank Miho Kobayashi, Makiko Kanaike and Yoshimi Sano for their secretarial assistance.

\section{Conflict of interest statement}

The authors have no conflicts of interest to declare.

\section{References}

1. Scheller B, Hehrlein C, Bocksch W, Rutsch W, Haghi D, Dietz U, Bohm M, Speck U. Treatment of coronary in-stent restenosis with a paclitaxel-coated balloon catheter. $N$ Engl J Med. 2006;355:2113-24.

2. Unverdorben $M$, Vallbracht $C$, Cremers $B$, Heuer $H$, Hengstenberg C, Maikowski C, Werner GS, Antoni D, Kleber FX, Bocksch W, Leschke M, Ackermann H, Boxberger M, Speck U, Degenhardt R, Scheller B. Paclitaxel-coated balloon catheter versus paclitaxel-coated stent for the treatment of coronary in-stent restenosis. Circulation. 2009;119:2986-94.

3. Habara S, Mitsudo K, Kadota K, Goto T, Fujii S, Yamamoto H, Katoh H, Oka N, Fuku Y, Hosogi S, Hirono A, Maruo T, Tanaka H, Shigemoto Y, Hasegawa D, Tasaka H, Kusunose M, Otsuru S, Okamoto Y, Saito N, Tsujimoto Y, 
Eguchi H, Miyake K, Yoshino M. Effectiveness of paclitaxel-eluting balloon catheter in patients with sirolimus-eluting stent restenosis. JACC Cardiovasc Interv. 2011;4:149-54.

4. Rittger H, Brachmann J, Sinha AM, Waliszewski M, Ohlow M, Brugger A, Thiele H, Birkemeyer R, Kurowski V, Breithardt OA, Schmidt M, Zimmermann S, Lonke S, von Cranach M, Nguyen TV, Daniel WG, Wohrle J. A randomized, multicenter, single-blinded trial comparing paclitaxel-coated balloon angioplasty with plain balloon angioplasty in drug-eluting stent restenosis: the PEPCAD-DES study. $J$ Am Coll Cardiol. 2012;59:1377-82.

5. Byrne RA, Neumann FJ, Mehilli J, Pinieck S, Wolff B, Tiroch K, Schulz S, Fusaro M, Ott I, Ibrahim T, Hausleiter J, Valina C, Pache J, Laugwitz KL, Massberg S, Kastrati A; ISAR-DESIRE 3 investigators. Paclitaxel-eluting balloons, paclitaxel-eluting stents, and balloon angioplasty in patients with restenosis after implantation of a drug-eluting stent (ISAR-DESIRE 3): a randomised, openlabel trial. Lancet. 2013;381:461-7.

6. Habara S, Iwabuchi M, Inoue N, Nakamura S, Asano R, Nanto S, Hayashi Y, Shiode N, Saito S, Ikari Y, Kimura T, Hosokawa J, Nakamura M, Kotani J, Kozuma K, Mitsudo K. A multicenter randomized comparison of paclitaxel-coated balloon catheter with conventional balloon angioplasty in patients with bare-metal stent restenosis and drug-eluting stent restenosis. Am Heart J. 2013;166:527-33.

7. Mehran R, Dangas G, Abizaid AS, Mintz GS, Lansky AJ, Satler LF, Pichard AD, Kent KM, Stone GW, Leon MB. Angiographic patterns of in-stent restenosis: classification and implications for long-term outcome. Circulation. 1999;100:1872-8.

8. Abe M, Kimura T, Morimoto T, Taniguchi T, Yamanaka F, Nakao K, Yagi N, Kokubu N, Kasahara Y, Kataoka Y, Otsuka Y, Kawamura A, Miyazaki S, Horiuchi K, Ito A, Hoshizaki H, Kawaguchi R, Setoguchi M, Inada T, Kishi K, Sakamoto H, Morioka N, Imai M, Shiomi H, Nonogi H, Mitsudo K; j-Cypher Registry Investigators. Sirolimus-eluting stent versus balloon angioplasty for sirolimus-eluting stent restenosis: Insights from the j-Cypher Registry. Circulation. 2010;122:42-51.

9. Agostoni P, Belkacemi A, Voskuil M, Nathoe HM, Doevendans PA, Stella PR. Serial morphological and functional assessment of drug-eluting balloon for in-stent restenotic lesions: mechanisms of action evaluated with angiography, optical coherence tomography, and fractional flow reserve. JACC Cardiovasc Interv. 2013;6:569-76.

10. Costa MA. Treatment of drug-eluting stent restenosis. Am Heart J. 2007;153:447-9.

11. Alfonso F, Pérez-Vizcayno MJ, Dutary J, Zueco J, Cequier A, García-Touchard A, Martí V, Lozano I, Angel J, Hernández JM, López-Mínguez JR, Melgares R, Moreno R, Seidelberger B, Fernández C, Hernandez R; RIBS-III Study Investigators (under the auspices of the Working Group on Interventional Cardiology of the Spanish Society of Cardiology). Implantation of a drug-eluting stent with a different drug (switch strategy) in patients with drug-eluting stent restenosis. Results from a prospective multicenter study (RIBS III [Restenosis Intra-Stent: Balloon Angioplasty Versus Drug-Eluting Stent]). JACC Cardiovasc Interv. 2012;5:728-37.

12. Alfonso F, Melgares R, Mainar V, Lezaun R, Vazquez N, Tascon J, Pomar F, Cequier A, Angel J, Perez-Vizcayno MJ, Sabate M, Banuelos C, Fernandez C, Garcia JM; Restensois Intrastent: Ballon angioplasty versus elective Stenting (RIBS) Investigators. Therapeutic implications of in-stent restenosis located at the stent edge. Insights from the restenosis intra-stent balloon angioplasty versus elective stenting (RIBS) randomized trial. Eur Heart J. 2004;25:1829-35.

13. Mintz GS, Popma JJ, Pichard AD, Kent KM, Satler LF, Wong C, Hong MK, Kovach JA, Leon MB. Arterial remodeling after coronary angioplasty: a serial intravascular ultrasound study. Circulation. 1996;94:35-43.

14. Tsunoda T, Nakamura M, Wada M, Ito N, Kitagawa $Y$, Shiba M, Yajima S, Iijima R, Nakajima R, Yamamoto M, Takagi T, Yoshitama T, Anzai H, Nishida T, Yamaguchi T. Chronic stent recoil plays an important role in restenosis of the right coronary ostium. Coron Artery Dis. 2004;15:39-44.

15. Alfonso F, Perez-Vizcayno MJ, Cardenas A, Garcia Del Blanco B, Seidelberger B, Iniguez A, Gomez-Recio M, Masotti M, Velazquez MT, Sanchis J, Garcia-Touchard A, Zueco J, Bethencourt A, Melgares R, Cequier A, Dominguez A, Mainar V, Lopez-Minguez JR, Moreu J, Marti V, Moreno R, JimenezQuevedo P, Gonzalo N, Fernandez C, Macaya C; RIBS V Study Investigators, under the auspices of the Working Group on Interventional Cardiology of the Spanish Society of Cardiology. A randomized comparison of drug-eluting balloon versus everolimus-eluting stent in patients with bare-metal stent-in-stent restenosis: the RIBS V Clinical Trial (Restenosis Intra-stent of Bare Metal Stents: paclitaxel-eluting balloon vs. everolimus-eluting stent). J Am Coll Cardiol. 2014;63:1378-86.

16. Byrne RA, Cassese S, Windisch T, King LA, Joner M, Tada T, Mehilli J, Pache J, Kastrati A. Differential relative efficacy between drug-eluting stents in patients with bare metal and drug-eluting stent restenosis; evidence in support of drug resistance: insights from the ISAR-DESIRE and ISAR-DESIRE 2 trials. EuroIntervention. 2013;9:797-802.

\section{Supplementary data}

Online Table 1. Baseline clinical, angiographic, and procedural characteristics (total population).

Online Table 2. Quantitative coronary angiographic analysis results. Online Table 3. Angiographic and clinical outcomes at 6 to 8 -month follow-up.

The supplementary data are published online at:

http://www.pcronline.com/

eurointervention/94th issue/223 


\section{Supplementary data}

Online Table 1. Baseline clinical, angiographic and procedural characteristics (total population).

\begin{tabular}{|c|c|c|c|c|c|c|c|}
\hline Total population & $\begin{array}{c}\text { PCB } \\
260 \text { patients }\end{array}$ & $\begin{array}{l}\text { Repeat DES } \\
425 \text { patients }\end{array}$ & $p$-value & Total population & $\begin{array}{c}\text { PCB } \\
306 \text { lesions }\end{array}$ & $\begin{array}{l}\text { Repeat DES } \\
471 \text { lesions }\end{array}$ & $p$-value \\
\hline Age, yrs & $69.2 \pm 9.9$ & $68.6 \pm 10.9$ & 0.42 & Non-focal type restenosis, $n$ (\%) & $205(67.0)$ & $215(45.7)$ & $<0.001$ \\
\hline Male gender, $\mathrm{n}(\%)$ & $195(75.0)$ & $331(77.9)$ & 0.40 & Stent edge restenosis, $\mathrm{n}(\%)$ & $23(7.5)$ & $117(24.8)$ & $<0.001$ \\
\hline Diabetes mellitus, $n(\%)$ & $134(51.5)$ & $231(54.4)$ & 0.48 & Aorto-ostial lesion, $n(\%)$ & $16(5.2)$ & $49(10.4)$ & 0.01 \\
\hline Hypertension, n (\%) & $203(78.1)$ & $318(74.8)$ & 0.36 & Bifurcation lesion, $n(\%)$ & $76(24.8)$ & $63(13.4)$ & $<0.001$ \\
\hline Hyperlipidaemia, n (\%) & $159(61.2)$ & $258(60.7)$ & 0.94 & Two-stent, n (\%) & 36 (11.8) & $13(2.8)$ & $<0.001$ \\
\hline Current smoker, n (\%) & $10(3.9)$ & $20(4.7)$ & 0.70 & Single-stent, $n(\%)$ & $40(13.1)$ & $50(10.6)$ & 0.30 \\
\hline Haemodialysis, $n(\%)$ & $24(9.2)$ & $54(12.7)$ & 0.17 & Stent fracture, $n(\%)$ & $48(15.7)$ & $96(20.4)$ & 0.11 \\
\hline Acute coronary syndrome, $\mathrm{n}(\%)$ & $22(8.5)$ & $62(14.6)$ & 0.02 & Previous DES type & & & $<0.001$ \\
\hline Stable angina, $\mathrm{n}(\%)$ & $238(91.5)$ & $363(85.4)$ & 0.02 & Paclitaxel-eluting stent, n (\%) & $51(16.7)$ & $91(19.3)$ & \\
\hline Multivessel disease, $n(\%)$ & $70(26.9)$ & $98(23.1)$ & 0.27 & \multicolumn{4}{|l|}{ Limus-eluting stent } \\
\hline Previous myocardial infarction, $\mathrm{n}(\%)$ & $133(51.2)$ & $220(51.8)$ & 0.94 & Sirolimus-eluting stent, $\mathrm{n}(\%)$ & $154(50.3)$ & $345(73.3)$ & \\
\hline Previous bypass surgery, $n$ (\%) & $23(8.9)$ & $27(6.4)$ & 0.23 & Zotarolimus-eluting stent, $\mathrm{n}(\%)$ & $51(16.7)$ & $16(3.4)$ & \\
\hline & 306 lesions & 471 lesions & & Everolimus-eluting stent, $n(\%)$ & $36(11.8)$ & $8(1.7)$ & \\
\hline Target lesion & & & 0.14 & Biolimus-eluting stent, $n$ (\%) & $14(4.6)$ & $11(2.3)$ & \\
\hline Left anterior descending, $n(\%)$ & $121(39.5)$ & $157(33.3)$ & & \multicolumn{4}{|l|}{ DES used for in-stent restenosis } \\
\hline Left circumflex, n (\%) & $48(15.7)$ & $63(13.4)$ & & Sirolimus-eluting stent, n (\%) & - & $177(37.6)$ & \\
\hline Right, n (\%) & $130(42.5)$ & $237(50.3)$ & & Paclitaxel-eluting stent, $\mathrm{n}(\%)$ & - & $164(34.8)$ & \\
\hline Left main trunk, $n(\%)$ & $7(2.3)$ & $14(3.0)$ & & Everolimus-eluting stent, n (\%) & - & $130(27.6)$ & \\
\hline Classification of in-stent restenosis & & & $<0.001$ & Stent diameter $(\mathrm{mm})$ & - & $2.97 \pm 0.39$ & \\
\hline Focal margin, $n(\%)$ & $5(1.6)$ & $87(18.5)$ & & Stent total length $(\mathrm{mm})$ & - & $19.7 \pm 12.5$ & \\
\hline Focal body, n (\%) & 96 (31.4) & $169(35.9)$ & & Multiple stents, n (\%) & - & $36(7.6)$ & \\
\hline Multifocal, n (\%) & $11(3.6)$ & $22(4.7)$ & & \multicolumn{4}{|l|}{ Paclitaxel-coated balloon } \\
\hline Diffuse, $n(\%)$ & $153(50.0)$ & $108(22.9)$ & & Balloon diameter (mm) & $2.88 \pm 0.44$ & - & \\
\hline Proliferative, $n(\%)$ & $18(5.9)$ & $30(6.4)$ & & Balloon total length $(\mathrm{mm})$ & $22.4 \pm 9.0$ & - & \\
\hline Occlusive, n (\%) & $23(7.5)$ & $55(11.7)$ & & Multiple balloons, n (\%) & $16(5.2)$ & - & \\
\hline Focal type restenosis, n (\%) & $101(33.0)$ & $256(54.4)$ & $<0.001$ & \multicolumn{4}{|c|}{ DES: drug-eluting stent; PCB: paclitaxel-coated balloon } \\
\hline
\end{tabular}

Online Table 2. Quantitative coronary angiographic analysis results.

\begin{tabular}{|c|c|c|c|}
\hline Total population & $\begin{array}{c}\text { PCB } \\
306 \text { lesions }\end{array}$ & $\begin{array}{l}\text { Repeat DES } \\
471 \text { lesions }\end{array}$ & $p$-value \\
\hline \multicolumn{4}{|l|}{ Pre-procedure } \\
\hline Diameter stenosis (\%) & $71.8 \pm 17.3$ & $70.8 \pm 17.3$ & 0.40 \\
\hline Minimal lumen diameter (mm) & $0.81 \pm 0.52$ & $0.86 \pm 0.54$ & 0.17 \\
\hline Reference diameter (mm) & $2.89 \pm 0.43$ & $2.99 \pm 0.48$ & 0.001 \\
\hline Lesion length (mm) & $17.1 \pm 8.6$ & $15.7 \pm 11.1$ & 0.046 \\
\hline \multicolumn{4}{|l|}{ Post procedure } \\
\hline Diameter stenosis (\%) & $28.8 \pm 9.6$ & $15.1 \pm 8.8$ & $<0.001$ \\
\hline Minimal lumen diameter (mm) & $2.08 \pm 0.45$ & $2.64 \pm 0.49$ & $<0.001$ \\
\hline Acute gain (mm) & $1.27 \pm 0.62$ & $1.78 \pm 0.66$ & $<0.001$ \\
\hline \multicolumn{4}{|c|}{ DES: drug-eluting stent; PCB: paclitaxel-coated balloon } \\
\hline
\end{tabular}


Online Table 3. Angiographic and clinical outcomes at 6 to 8-month follow-up.

\begin{tabular}{|c|c|c|c|c|c|c|c|}
\hline Total population & $\begin{array}{c}\text { PCB } \\
260 \text { patients } \\
\text { (306 lesions) }\end{array}$ & $\begin{array}{l}\text { Repeat DES } \\
425 \text { patients } \\
\text { (471 lesions) }\end{array}$ & $p$-value & $\begin{array}{l}\text { Unadjusted HR } \\
\text { (95\% CI) }\end{array}$ & $p$-value & $\begin{array}{l}\text { Adjusted HR } \\
\text { (95\% CI) }\end{array}$ & $p$-value \\
\hline Angiographic follow-up at 6 to 8 months (per lesion) & $281 / 306(91.8 \%)$ & $409 / 471(86.8 \%)$ & & & & & \\
\hline Diameter stenosis (\%) & $41.8 \pm 18.5$ & $37.2 \pm 23.8$ & 0.005 & & & & \\
\hline Minimal lumen diameter (mm) & $1.73 \pm 0.64$ & $1.98 \pm 0.82$ & $<0.001$ & & & & \\
\hline Late luminal loss (mm) & $0.34 \pm 0.57$ & $0.68 \pm 0.76$ & $<0.001$ & & & & \\
\hline Binary restenosis, $n(\%)$ & $66(23.5)$ & $106(25.9)$ & 0.48 & $1.03(0.75-1.39)$ & 0.86 & $0.81(0.58-1.11)$ & 0.19 \\
\hline Target lesion revascularisation, $\mathrm{n}(\%)$ & $44(15.7)$ & $83(20.3)$ & 0.13 & $0.83(0.57-1.19)$ & 0.30 & $0.70(0.47-1.02)$ & 0.06 \\
\hline Clinical follow-up at 12 months (per patient) & $258 / 260$ (99.2\%) & $422 / 425(99.3 \%)$ & & & & & \\
\hline Target lesion revascularisation, $n$ (\%) & $43(16.7)$ & $82(19.4)$ & 0.41 & $0.84(0.57-1.21)$ & 0.35 & $0.74(0.50-1.09)$ & 0.13 \\
\hline Cardiac-related death, n (\%) & $0(0)$ & $7(1.7)$ & 0.049 & - & - & - & - \\
\hline Myocardial infarction, n (\%) & $0(0)$ & $1(0.2)$ & $>0.99$ & - & - & - & - \\
\hline Target lesion thrombosis, n (\%) & $0(0)$ & $1(0.2)$ & $>0.99$ & - & - & - & - \\
\hline MACE, n (\%) & $43(16.7)$ & $85(20.1)$ & 0.27 & $0.81(0.56-1.16)$ & 0.26 & $0.75(0.50-1.09)$ & 0.13 \\
\hline
\end{tabular}

